1 OD, Papers 4: 416; PM, Introduction, Chap. 3.

russell: the Journal of Bertrand Russell Studies n.s. 27 (summer 2007): 106-24

The Bertrand Russell Research Centre, McMaster U. issn 0036-01631 


\title{
SOME REMARKS ABOUT RUSSELLIAN INCOMPLETE SYMBOLS
}

\author{
Sébastien Gandon \\ phier / U. Blaise Pascal \\ 63000 Clermont-Ferrand, France \\ sgandon@wanadoo.fr
}

\begin{abstract}
Russellian incomplete symbols are usually conceived as an analytical residue - as what remains of the would-be entities when properly analyzed. This article aims to reverse the approach in raising another question: what, if any, does the incomplete symbol contribute to the completely analyzed language? I will first show that, from a technical point of view, there is no difference between the way Russell defines his denoting phrases in "On Denoting" and the way Frege defines his second-order concepts. But I will secondly support that the two notions have two widely different conceptual meanings: the same logical procedures which are used by Frege to increase the deductive power of his system allow Russell to logically relate quantificational notation to ordinary language. Focusing on Russell's treatment of $O D$ 's puzzles, I will thirdly argue that this shift constitutes the source of a deep transformation in the way logic and language are related.
\end{abstract}

What, in "On Denoting" and in the introduction to the Principia", are incomplete symbols? At first sight, this question seems rather curious. Indeed, the status of the incomplete symbol is clear enough in $O D$ : an incomplete expression is a syntactic object, a mere sign without any meaning in itself. Besides, the issue addressed by Russell is not this one. He wants to explain how to give up his old theory of denotation, that is: how to view what was previously considered a name of a denoting concept as an incomplete symbol. He does not want to characterize what an incomplete symbol is.

No surprise then, if, more often than not, an incomplete symbol is viewed by Russellian scholars as just an analytical residue. The standard interpretation holds that, in $O D$, definite descriptions are no more than incomplete symbols - which means that they are nearly nothing. Incomplete symbols name nothing, they do not belong to the substantial (logical) content, they are just some marks that belong to a surface linguistic form, which has nothing to do with the genuine logical form. If terms like "proposition", "meaning", "denotation" are not language-dependent, the notion of "incomplete symbol" is for Russell not a logical but a linguistic one ${ }^{2}$.

Even if I, with most Russell scholars, regard the eliminativistic stance as the main import of $O D$, I think that people are wrong to consider the notion of incomplete symbol as a mere banal linguistic notion, without any logical importance. By comparing Frege with Russell, I will try to show that this notion is much more mysterious and interesting than usually believed. It seems to me that bringing incomplete symbols to the foreground reveals a new conception of the relations between logic and ordinary language. I will argue Wrst that Russellian descriptions could be viewed, from a logical point of view, as second-order concepts. I will move on to defend the view that, if Russell himself does not regard $O D$ 's incomplete symbols as quantifiers, the use he makes of his definition is supported by a new

\footnotetext{
${ }^{1}$ OD, Papers $4: 416 ;$ PM, Intro., chap. 3.

${ }^{2}$ See, for example, P. Hylton, Russell, Idealism, and the Emergence of Analytical Philosophy (Oxford: Clarendon P., 1990). But Hylton stresses, as I will do, the logical importance of the distinction between surface and logical form.
} 
kind of relation between the linguistic and logical levels of analysis. Finally, I will illustrate the new division between these levels by a close examination of the notion of a puzzle that Russell appeals to in $O D$.

I- It is customary today to draw an analogy between the Fregean discovery of the quantificational notation, which enables us to write:

(1) B(all F)

as a formal implication,

(1') $\forall \mathrm{x}(\mathrm{Fx} \Rightarrow \mathrm{Bx})$

and the Russellian discovery which allows us to write:

(2) B(the Fy)

as an existential proposition,

(2') $\exists \mathrm{x}(\mathrm{Fx} \wedge \forall \mathrm{y}(\mathrm{Fy} \Rightarrow \mathrm{y}=\mathrm{x}) \wedge \mathrm{Bx})$.

In The Principles of Mathematics, Russell, unlike Frege, considered that a proposition like (1) was completely analyzed. The words "All F" were then conceived of as the name of an entity (the denoting concept).

Because he gets rid of this kind of concept, Russell's move in $O D$ could be interpreted as a return to a position which was already the one taken by Frege in 1879. The "the-phrase" is for Russell in $O D$ just the same as the "all-phrase" was for Frege: a linguistic residue that logicians and philosophers can neglect if they want to display the true form of the sentences containing them.

But this parallel between Frege and Russell raises a slight problem. In a Fregean perspective, nothing prevents one from attributing a reference to the symbol "all F". Let's assume that hx is a first-order function variable, and that $\mathrm{Fx}$ is a name of a first-order function; does the definiens of:

$$
\mathrm{h}(\mathrm{All} \mathrm{F})=\forall \mathrm{x}(\mathrm{Fx} \Rightarrow \mathrm{Bx}) \quad \mathrm{Df}
$$

define something for Frege?

In the Grundgesetze der Arithmetik, §30, Frege gives two rules which allow an extension of the ideographic vocabulary. The first one says that the result of the combination of an unsaturated expression and the name of an object is a new sign of an object. The second one (the important one for us) says that you can extract from a saturated expression the name of a function by removing one (or many) of its sign(s) for objects or functions. ${ }^{3}$

The definition (3) can be considered as an application of this second rule. According to it, we create a new symbol by "removing" the function "Bx" from the expression " $\forall \mathrm{x}(\mathrm{Fx} \rightarrow \mathrm{Bx})$ " (by replacing "Bx" by "hx"). That means that Frege would have taken the definition (3) as a legitimate definition of a symbol of a second-order function - of course, under the hypothesis that Fx and Bx have a denotation. "All-phrases" would be considered by Frege as a kind of quantifier. (3) could be written as

$$
\forall_{\mathrm{F}} \mathrm{x}(\mathrm{hx})=\forall \mathrm{x}(\mathrm{Fx} \Rightarrow \mathrm{hx}) \text { Df }
$$

where " $\forall_{\mathrm{F}} \mathrm{x}$ " is the name of a second-order function (a quantifier).

\footnotetext{
${ }^{3}$ Frege, Grundgesetze der Arithmetik, Vol. i, $\$ 30$, quoted in the translation of M. Furth, The Basic Laws of Arithmetic: Exposition of the System (Berkeley: U. of California P., 1964), p. 85: "The foregoing provisions are not to be regarded as definitions of the phrases "have a denotation" or "denote something", because their application always presupposes that we have already recognized some names as denoting. They can serve only in the extension step by step of the sphere of such names. From them it follows that every name formed out of denoting names does denote something. This formation is carried out in this way: a name fills the argument-places of another name that are fitting for it... The names so formed may be used in the same way for the formation of further names, and all names arising in this way succeed in denoting if the primitive simple names do so.... [W] e see the possibility of a second procedure for forming names of first-level functions. To wit: we begin by forming a name in the first way, and we then exclude from it at all or some places a proper name that is part of it ... but in such a way that these places remain recognizable as argument-places of type 1 . The function-name resulting from this likewise always has a denotation if the simple name from which it is formed denotes something; and it may be used further to form denoting names in the first way or in the second."
} 
Frege explicitly bases some of his analysis on (4). For instance, in order to show that the phrase "all mammals" in the sentence

(5) All mammals are land-dwellers

is not the logical subject of the predicate, Frege points out that the negation of (5) is not "all mammals are not land-dwellers" but "it is not true that all mammals are land-dwellers", "from which it follows that 'all' logically belongs to the predicate." We could use (5) to understand what Frege means. The negation of (4) is not:

but

$$
\forall_{\mathrm{M}} \sim \mathrm{Lx}
$$

$$
\sim \forall_{\mathrm{M}} \mathrm{xLx} .
$$

A logical mistake would be to take the "all-phrase" as the name of an object (the subject of a predicate) — but taking the "all-phrase" as the name of a second-order function is not erroneous.

Let's go back to Russell and the definite description. As I have said, the incomplete symbol is often considered a residue - as what remains when we have completely analyzed ordinary language. In order to break with this approach, I will ask you to imagine for a moment that we live in a world where men never use ordinary language (language with definite descriptions), but only and directly standard quantificational language.

And I will ask you to consider the form

(6) $\quad[\mathrm{lxFx}] \mathrm{h}(\mathrm{lx})(\mathrm{Fx})=\exists \mathrm{x}(\mathrm{Fx} \wedge \forall \mathrm{y}(\mathrm{Fy} \Rightarrow \mathrm{y}=\mathrm{x}) \wedge \mathrm{hx}) \quad \mathrm{Df}$,

not as an analysis, but as a definition of a new symbol.

In other words, I will ask you to interpret the Russellian analysis of the definite description as a synthesis - to read (6) not from left to right, but from right to left. I know that this reading is a bit perverse, but identity is a symmetrical sign, and nothing except habit compels us to favour the one direction rather than the other.

If you read (6) from right to left, you will recognize (6) as an instance of the second Fregean rule. In (6) as in (4), a name of a second-order concept is formed by "deleting" the function "Bx" from respectively the propositions (2') and (1'). In (6) as in (4), the logical processes are the same: a new concept is created by excluding a name of a first-order function at one of its places in the proposition. If you look at (6) that way, that is, if you try to characterize in (6) the definiendum by the definiens, you will identify the descriptive symbol as a new kind of quantifier. Following the Fregean path, we could introduce a second-order concept " $\Delta_{\mathrm{F}} \mathrm{x}(h \mathrm{x})$ " by the definition

(7) $\quad \Delta_{\mathrm{F}} \mathrm{x}(\mathrm{hx})=\exists \mathrm{x}(\mathrm{Fx} \wedge \forall \mathrm{y}(\mathrm{Fy} \Rightarrow \mathrm{y}=\mathrm{x}) \wedge \mathrm{hx}) \quad$ Df.

And by transitivity of identity, it will result in:

(8) $\quad[\mathrm{lxFx}] \mathrm{h}(\mathrm{lx})(\mathrm{Fx})=\Delta_{\mathrm{F}} \mathrm{x}(\mathrm{hx})$

which means that Russellian incomplete symbols are Fregean second-order concepts.

This analysis is not new. Geach already suggested a conception along these lines: he compared the Russellian word "incomplete" with the Fregean term "ungesättigt". 5 And much

\footnotetext{
${ }^{4}$ Frege, "On Concept and Object", in Translations from the Philosophical Writings of G. Frege, ed. P. Geach and M. Black (Oxford: Blackwell, 1952), p. 48: "It must be remarked here that the words "all", "any", "no", "some", are prefixed to concept-words. In universal and particular affirmative and negative sentences, we are expressing relations between concepts; we use these words to indicate the special kind of relation. They are thus, logically speaking, not to be more closely associated with the concept-words that follow them, but are to be related to the sentence as a whole. It is easy to see this in the case of negation. If in the sentence "all mammals are land-dwellers" the phrase "all mammals" expressed the logical subject of the predicate are land-dwellers, then in order to negate the whole sentence we should have to negate the predicate: "are not land-dwellers". Instead, we must put "not" in front of "all"; from which it follows that "all" logically belongs with the predicate."

${ }^{5}$ Geach and Black, eds., Translations, p. 51: "When Russell says that expressions like 'the King of France' are not names but incomplete symbols, he is saying what would be put thus in Frege's terminology: "In "the King of France is bald", "the King of France" is not a name of an object; what it stands for is something incomplete, ungesättigt - a second-level concept, within which the concept bald is falsely asserted to fall." More recently, S. Neale, in his Descriptions (Cambridge: M.I.T. P.,
} 
could be said, from a logical point of view, for such a parallel. Thus, the difference between the occurrences of a definite description symbol could be very easily explained if you take them to be quantifiers. In the Principia, Russell links the definite description symbol to a scope and the scope is, in Frege's Grundgesetze, what makes the argument of a second-order function recognizable. So, the puzzle of the King of France could be explained using exactly the same remarks Frege makes about the negation of "all mammals are landwellers".

If we take into account the scope, we see that the negation of "the King of France is bald" is not (9) but (10):

(9) $\quad[\mathrm{lxFx}] \sim \mathrm{B}(\mathrm{lx})(\mathrm{Fx})=\Delta_{\mathrm{F}} \sim \mathrm{Bx}=\exists \mathrm{x}(\mathrm{Fx} \wedge \forall \mathrm{y}(\mathrm{Fy} \Rightarrow \mathrm{y}=\mathrm{x}) \wedge \sim \mathrm{Bx})$

(10) $\sim[\mathrm{lxFx}] \mathrm{B}(\mathrm{lx})(\mathrm{Fx})=\sim \Delta_{\mathrm{F}} \mathrm{BBx}=\sim \exists \mathrm{x}(\mathrm{Fx} \wedge \forall \mathrm{y}(\mathrm{Fy} \Rightarrow \mathrm{y}=\mathrm{x}) \wedge \mathrm{Bx})$.

The Fregean framework could thus be used to characterize the definite description symbol from the way it is defined. The definiens of the description symbol is the definiens of a Fregean second-order concept - furthermore, the way Russell talks about these incomplete symbols could be easily recovered in taking them as names of second-order concepts.

II- Nevertheless, I do not think that Russellian descriptions are second-order concepts. Indeed, a Russellian description is an incomplete symbol, i.e. a sign that designates nothing. I do, however, think that making such a parallel between these phrases and second-order concepts is a good antidote against the standard view that tends to treat definite description expressions as mere residues. The notion of an incomplete symbol is, in $O D$, logically as elaborated as the notion of a second-order concept in the Grundgesetze. What it involves in terms of scope is here as sophisticated as there. And the question of scope delimitation can be very intricate $^{6}$, as the problem of formulating appropriate substitution rules in the predicate logic shows. The theory of the incomplete symbol in $O D$ is a logical theory, just like the theory of the concept in Frege's work.

The parallel which has just been drawn between Frege and Russell is significant because it allows a shift in the formulation of the initial question. The thing we need to explain is no longer how Russell can dispense with "unwelcome objects", but it is from now on how Russell can believe that the definite description, as he defines it, is a mere sign deprived of any meaning. How are we to explain that something which is characterized as a mere linguistic device, without any logical meaning, could at the same time be defined by logical means?

Let's go back to Frege. Why does Frege want to form new concepts? The expansion of the ideographic terminology is needed for increasing the deductive power of the logical system. For example, by contraposing Law IIa of the Grundgesetze ("what holds for all first-order functions of one argument holds also for any"), and by assuming that Bx is a first-order function, from (2') $\exists \mathrm{x}(\mathrm{Fx} \wedge \forall \mathrm{y}(\mathrm{Fy} \Rightarrow \mathrm{y}=\mathrm{x}) \wedge \mathrm{Bx})$, it is possible to make the deduction:

$$
\frac{\exists \mathrm{x}(\mathrm{Fx} \wedge \forall \mathrm{y}(\mathrm{Fy} \Rightarrow \mathrm{y}=\mathrm{x}) \wedge \mathrm{Bx})}{\exists \mathrm{f} \Delta_{\mathrm{F}} \mathrm{x}(\mathrm{fx})}
$$

But in order to do that, we must prove that the right-hand side of (7), $\exists x(F x \wedge \forall y(F y \Rightarrow y=x)$ $\wedge \mathrm{hx}$ ), has a reference - and that is where the second Fregean law comes in. So, for Frege, "the extension step by step of the sphere of the logical names" is needed for carrying out the

1990), has argued that definite descriptions must be considered as a kind of quantifier. As it soon will be clearer, I do not support this view. By (7), I just want to stress that, given the way Russell defines them, definite descriptions could have been considered as second-order functions

${ }^{6}$ See, for instance, P. de Rouilhan, Russell et le cercle des paradoxes (Paris: PUF, 1996), pp. 119-20. 
logicist programme - that is, for carrying out the logical deduction of all mathematics from a restricted number of logical premisses.

However, Frege very often says that the definitions are logically superfluous and that they are only introduced for material convenience. ${ }^{7}$ This claim seems to contradict what we have just said about the fundamental role of the second Fregean law in the logical working of the ideographic system. How could the expansion of the ideographic vocabulary be said to be both essential and redundant to the logicist programme? Even if this question is more a matter for Fregean scholarship, I will push its examination further because a deepening of the analysis will shed some light on the Russellian stance.

In the Grundgesetze, $\$ 28$, Frege says that definition is the introduction of a new name. Can we assimilate definition to the logical formation of new names described in Grundgesetze, $\S 30$ ? I do not think so. We must take care not to conflate too quickly concept-formation and definition. The Fregean rules secure that a newly defined sign has a reference. Thus, considered in themselves, the rules do not have anything to do with the procedure of definition, i.e. with the introduction of a new sign. We could apply the second rule in (11) without introducing the sign " $\Delta_{\mathrm{F}} \mathrm{x}(\mathrm{hx})$ " to name what " $\exists \mathrm{x}(\mathrm{Fx} \wedge \forall \mathrm{y}(\mathrm{Fy} \Rightarrow \mathrm{y}=\mathrm{x}) \wedge \mathrm{Bx})$ " designates. In order to do the deduction (11), we must establish that the right-hand side of (7) is a second-order concept - and to guarantee that this is the case, the second Fregean law will suffice.

I suggest that the distinction between definition and concept-formation, first made in the Grundgesetze, can nicely explain the evolution of Frege's thought. Dummett ${ }^{8}$ convincingly argues that, before 1893, Frege regarded the definition as logically essential. From our point of view, this Fregean stance is an immediate consequence of the confusion made at that time between definition and concept-formation. In the Begriffsschrift, §24, for instance, the concept "hereditarity of a first-order function $F$ in an $f$-sequence" is introduced through a symbolic device that designates it. ${ }^{9}$ More generally, all the deductions made by Frege in 1879 are presented with a schema that guides the reading of the different premisses, and that shows how the substitution should be made. When the proofs become intricate, it is absolutely essential to have some new names to put in the substitution-places of the schemas. Thus, in the Begriffsschrift, the definitions play the role of the substitution rules, and it is thus understandable that Frege takes them to be logically essential.

In the Grundgesetze, the distinction he introduces between concept-formation and definition allows him to reserve the definition for a role of secondary importance. The logicist programme and the required substitutions can be developed without introducing any new signs - even if it is very difficult for a human mind to grasp the way the propositions must be decomposed without having a means to designate their different parts.

To say that the two laws of $\S 30$ are essential, then, does not contradict, for Frege (in the Grundgesetzez), the claim according to which the definitions are logically superfluous. For the philosopher, the definition is just, at this time, a symbolic device allowing us to recognize an already formed concept.

\footnotetext{
${ }^{7}$ This is a leitmotiv of the Grundgesetzez; cf. introduction (p. 2, Furth edn.: "The definitions do not really create anything, and in my opinion may not do so; they merely introduce abbreviated notations ... which could be dispensed with were it not that lengthiness would then make for insuperable external difficulties") and ii, §§86-137. Cf. Frege, Posthumous Writings, ed. H. Hermes et al. (Oxford: Blackwell, 1979), pp. 69, 208.

${ }^{8}$ The Interpretation of Frege 's Philosophy (London: Duckworth, 1991), p. $337 \mathrm{f}$.

${ }^{9}$ Begriffsschrift, \$24, quoted in From Frege to Gödel - a Source Book in Mathematical Logic, 1879-1931, ed. J. van Heijenoort (Cambridge, Mass.: Harvard U. P., 1967), p. 55: "Our sole purpose in introducing such definitions is to bring about an extrinsic simplification by stipulating an abbreviation. They serve besides to emphasize a particular combination of signs in the multitude of possible ones, so that our faculty of representation can get a firmer grasp of it."
} 
It is as if Russell, in $O D$, conflated concept-formation and name-introduction into one operation: the application of the second Fregean law is not viewed in (6) as a conceptformation, but just as a definition.

For Russell, what is synthesized is not, as in the Grundgesetze, a concept; it is not even a new name for a concept, as in the Begriffsschrift; it is a mere symbol, with no meaning in itself. Frege, in 1893, distinguishes between a conceptual creation and a sign introduction. Russell cannot make such a distinction: for him, forming a incomplete symbol is introducing a new expression. Russell uses exactly the same logical procedure as Frege; but he regards the result of its application as a new form of expression, which does not reflect the logical articulation of the proposition any more. The possibility of decomposing the same proposition into alternative ways is no longer viewed as a logical one. It is conceived as a way of generating a given linguistic form from another one. Thus, the logical side of the Fregean distinction collapses into the epistemological one: what was regarded as a concept-formation is now no more than the creation of a new form of expression.

We could state the facts slightly differently. Does Russell in $O D$ think that the incomplete symbol he defines is essential to the logicist programme? Russell could need to make the kind of derivation presented in (11). But he would then introduce a second-order propositional function to do the job. Russell would not use an incomplete symbol to make such a deduction. ${ }^{10} 10$ For him, an incomplete expression has no meaning: it cannot be a value of a variable and cannot (PM 1: 67) then be used carelessly in a proof. Russell always stresses that incomplete expressions can be eliminated from the completely analyzed language, and that all mathematics can be derived without using such a device. Incomplete expressions are logically superfluous. So, if not for constructing new inference chains, what are Russell's reasons for introducing descriptions?

Russell uses his definition to logically explain the relation between different notations:

(i) In $O D$, the application of what is an equivalent of the Fregean second law does not transform a combination of logical symbols into a new logical name belonging to the same language. What is synthesized here is a symbol belonging to a new notation. The Fregean law no longer expands the vocabulary of the logical language; it establishes a link between the concept-notation and another language. Russell uses the same logical quantificational procedure as Frege - but this use has not the same meaning it has for Frege.

(ii) Conversely, the relation between ordinary language and the completely analyzed symbolism is, in $O D$, considered a logical one. Russell, as well as Frege, distinguishes the concept-notation and ordinary language. But, for Frege, ordinary language is logically incoherent; it is therefore impossible, from a Fregean perspective, to settle precise rules of translation between ordinary language and ideography. ${ }^{11}$ Unlike Frege, Russell thinks that the relation between different languages is capable of being logically investigated. $O D$ 's import is precisely to show how a translation in quantificational notation can explain the logical working of ordinary symbolism. ${ }^{12}$

\footnotetext{
${ }^{10}$ Russell could have introduced a second-order propositional function: $\exists x(F x \wedge \forall y(F y \Rightarrow y=x) \wedge h x) —$ which, in English, is the property for a property to be attributed to the King of France. Is the propositional function the same thing as the incomplete symbol? My answer is no. The question is linked with the one which concerns the status of propositional functions. Several scholars have argued that propositional functions are not terms; see G. Landini, Russell's Hidden Substitutional Theory (New York: Oxford U. P., 1998); B. Linsky, Russell's Metaphysical Logic (Stanford: csli Publications, 1999); J. Levine, "Analysis and Decomposition in Frege and Russell", Philosophical Quarterly 52 (2002): 195-216. But in the Principia, at least, a distinction is made between the two concepts.

${ }^{11}$ Frege is particularly clear on this point in "Logic in Mathematics" (Posthumous Writings, pp. 224-9). See for instance the distinction between analytical and constructive definition.

${ }^{12}$ Compare this to what Russell says about the artificiality of Frege's solution. Unlike Frege, Russell does not allow ad hoc procedures which move logical notation away from the ordinary ("natural") one, as, for example, the decision to give the null-class as denotation of "the King of France" when there's no King of France. He prefers to outline the logical structure of the natural language.
} 
In $O D$, the object assigned to logical theory changes. Logic is no longer what it was in the Grundgesetze or in the Principles, i.e. a theory of certain very general language-independent structures. Logic is, from now on, applied to the relation between different notational devices. ${ }^{13}$ The following diagrams will help to visualize the opposition between Frege and Russell, as I see it:

- FREGE

Logical language: device for proof

Simple name

new names

Formation rules $(G g \S 30)$

Contextual definition $(O D)$

Ordinary language

(not logically in order)

- RUSSELL

Ordinary language

Contextual definition $(G g \S 30)$

Formation rules $(O D)$

\author{
Logic as a means \\ of translation
}

\title{
Logical language: device for proof
}

There are two correlated differences in these schemas, which reflect the two points distinguished above: (i) a difference on how to use logic: for Russell, logic can be used to construct proofs and to construct translations (logic is used twice) - for Frege, it is absurd to undertake a translation from ordinary to logical language; (ii) a difference on the status of ordinary language: for Frege, the working of ordinary notations is not logical; for Russell, ordinary languages are in order as they are. I emphasize that these two correlated differences could be grasped thanks only to the closeness of the logical procedure used both by Russell and Frege.

III- I have said that it was not enough to say that Russell's incomplete symbols were not linguistic. I hope that this general claim is starting to be more plausible. Description symbols are not only what remains when we have analyzed ordinary language - like the dead skin sloughed off by a snake. Incomplete symbols have a logical content which is displayed by the contextual definition. At the same time, definite descriptions are not second-order concepts; they are just symbols. It is thus the notion of language, and the relation between symbolism and logic, which come to the fore in $O D$. The meaning of both logic and language changes, and that's why I think that an opposition between the question of language and the question of logic could be an impediment to understanding $O D$. But what is the meaning of such an extension of the logical domain?

\footnotetext{
${ }^{13}$ In $O D$, the other language which is related to the logical one is ordinary English. But in the Principia, the "non-logical" notation is the ordinary language of working mathematicians. Russell takes as an instance of an incomplete symbol the differential notation (this same example is used by Frege to illustrate what a second-order function is).
} 
What are the consequences of this logicisation of linguistic questions? Are there any texts where Russell confronts these problems?

I haven't found any place where Russell developed his analysis along the lines I have drawn. Russell never seems to realise that his practice is very different from Frege's. So, couldn't we regard this apparent lack of awareness as a symptom of the weakness of my interpretation? Maybe I have overemphasised, above, a tiny difference between Frege and Russell without having been able to recognize the huge platform of their shared assumptions.

But let's try, for a moment, to follow the path we have started to take. Even if Russell nowhere says that, in $O D$, the relation between the completely analysed language and usual notations becomes a logical one, I would like to show that the new role assigned de facto to logic is not without any effects on Russell's thought. I will try to point out that this difference affects the way Russell deals with the puzzles.

$O D$-puzzles could be described as instances of a contradiction between the application of certain logical laws and the application of certain usual grammatical rules. Let's consider, for instance, the second puzzle. The law of excluded middle stipulates that a proposition or its negation is true; in accordance to this law, "the present King of France is bald" or "the present King of France is not bald" would have to be false. Now, as France was in 1905 a Republic, no King of France belonged either to the class of the bald entities or to its complementary. According to what may be called the usual rules of predication, the two propositions are false - which goes directly against the law of excluded middle.

So described, the situation in $O D$ is very similar to the one dealt with by Frege in his answer to Kerry (On Concept and Object), who had criticised him for holding that the concept horse is not a concept. Here as there, a logical law (the one which stipulates that a concept is unsaturated) is contradicted by an ordinary grammatical rule (the rule of "subordination of concept" which makes us say that "the town Berlin is a town", and therefore that "the concept horse is a concept" $)^{14}$. Of course, the Fregean problem and the $O D$ puzzles are not the same. But, in so far as they both involve contradiction between logical laws and ordinary grammatical rules, it seems to me possible to compare them.

For Frege, the "concept horse"'s problem does not belong properly to logic, but comes from a kind of mix-up between two meanings of the term concept. Frege explains that if you adopt the point of view of the usual language, you do not find any paradox. The sentence "the concept horse is not a concept" is rejected as trivially false by any English speaker. Now, if you adopt the very different point of view of the ideography, you do not meet any puzzle either. In the Fregean logical notation, the concept-sign shows that concepts can't become arguments of first-order functions. In that framework, you can't even formulate the problematic sentence ${ }^{15}$. To sum up, the usual language being logically imperfect, the English speaker cannot be, in Frege's opinion, embarrassed by the disharmony between the rules of his language and the external laws of the ideography; but the concept-notation being perfect, the logician cannot either be troubled by this kind of problem. So, according to Frege, there is really no puzzle.

It is no surprise, then, if Frege doesn't give a proper answer to Kerry. He says to him that he must choose between two different systems of notation, and that once the choice has been made, all will be settled ${ }^{16}$. Frege goes just a bit further in holding that he cannot explain the working of the basic features of his conceptual notation in using the ordinary language. A

\footnotetext{
${ }^{14}$ On Concept and Object, in Geach ed., Translations..., p. 46.

${ }^{15}$ At best, a translation of "the concept horse is not a concept" transforms the puzzling proposition into an absolutely not puzzling logical truth : $\forall \mathrm{x}(\mathrm{x}$ is a horse $\mathrm{v} \sim \mathrm{x}$ is a horse). See Dummett, Frege's Philosophy of Language, London : Duckworth, 1971, p. 216-217; for further discussion, see Weiner, Frege in Perspective, Londres : CUP, 1990, p. $255-256$.

${ }^{16}$ Frege, On Concept and Object, in Translations..., p. 54 : "I do not at all dispute Kerry's right to use the words "concept" and "object" in his own way, if only he would respect my equal right, and admit that with my use of terms I have got hold of a distinction of the highest importance."
} 
logical fundamental difference can't be expressed with a medium which is in itself logically imperfect. That's why Frege asks his reader for understanding and goodwill.

Let's go back to $O D$. Unlike Frege, Russell takes the puzzles very seriously. In $O D$, it is the English speaker himself who is embarrassed. The puzzles do not come from an outsider (from a reader who is unwilling to go along), but from Russell himself. Russell takes over the Meinongian questions; they puzzle him as much as they puzzled Meinong. The fact that the application of usual semantical rules contradicts logical laws means, for the English speaker himself (and then for Russell), that the working of his language has not been captured - and not, as Frege believed, that this working is illogical. The puzzles, in $O D$, are not the symptoms of a want of order; they are the symptoms of the difficulties in grasping an order that is in itself logically perfect. But this is not the only, or even, the most important, difference. While Frege states that it is not even possible to formulate the concept-horse puzzle in his ideography, Russell shows how a logical theory can explain his puzzles. What does "solving the puzzles" mean in $O D$ ? Solving the puzzles is not, for Russell, to have them translated into standard logical notation. When you make such a translation (and Frege is right on this point), you lose sight of what is puzzling in the puzzles. For Russell, solving the puzzles means recognizing the scope that the incomplete symbol has in the sentences belonging to ordinary language. It is thus the delimitation of the place of the negation, inside or outside the definite description's scope, which solves the puzzle (see (9) and (10)). Thus Russell starts with the very symbol the English speaker uses (the definite description) to recover, through it, the logical order. Russell does not leave ordinary language to eliminate the problem - as Frege does. This point shows that ordinary notation is not, for Russell, the source of the puzzle. Ordinary language, as the scope notation of the Principia indicates, is in order as it is - it can express the distinction between primary and secondary occurrences of the description.

But if ordinary language is in order, how are we to explain the emergence of the puzzles? As Russell says, in usual circumstances, the interpretation (9), where the definite description has a primary occurrence, is the right one. ${ }^{17}$ So, if you take into account what is usually present in the context of the utterance of "the King of France is not bald", you will say that this sentence is not the negation of "the King of France is bald". But, if you take into account only the written form of the sentence (what you can call, following Wittgenstein, the sign of the symbol — "the part of the symbol perceptible by the senses" [Tractatus, 3.32]), you will be puzzled.

Then the puzzle does not come, for Russell, from ordinary language itself, but from an excessive attachment to the perceptible part of a symbol — to the sign of the symbol. For Russell, the implicit conventions which govern the use of a sign in ordinary language belong to this language; and these conventions always determine the scope of the description symbol. ${ }^{18}$ It is the neglect of these conventions, of "the significant use" of the sign, as Wittgenstein (Tractatus, 3.326) would have put it, which is both the cause of the puzzle and of the belief that ordinary language is illogical.

Otherwise said, I do not think that the scope notation of the Principia represents a change to ordinary language. The introduction of the scope symbol is just a means to make apparent in regard to the ordinary sentence itself what is already present, but left implicit, in its use. This

\footnotetext{
${ }^{17} P M$ I: 69: "It should be observed that such a proposition as $\sim f\{(x)(\phi x)\}$ is ambiguous; it may deny $f\{(1 x)(\phi x)\}$, in which case it will be true if $(1 x)(\phi x)$ does not exist, or it may mean $\exists c(\forall x(\phi x \Leftrightarrow x=c) \wedge \sim f)$, in which case it can only be true if $(l x)(\phi x)$ exists. In ordinary language, the latter interpretation would usually be adopted. For example, the proposition 'the King of France is not bald' would usually be rejected as false, being held to mean 'the King of France exists and is not bald', rather than 'it is false that the King of France exists and is bald'."

${ }^{18}$ This constitutes another big difference between Frege and Russell. Contrary to Russell, Frege thought that there is a logical superiority of the written over the oral form of language.
} 
scope device, far from being part of an alien symbolism, enables the English speaker who is lost in his language to recognize how his own (unanalyzed) notation works.

What has just been said about the puzzles could be applied to the story of the yacht owner and his unpleasant guest:

I have heard of a touchy owner of a yacht to whom a guest, on first seeing it, remarked, "I thought your yacht was larger than it is"; and the owner replied, "No, my yacht is not larger than it is". (OD, Papers 4: 424)

If you translate the remark of the guest and the reply of the touchy owner into the standard quantificational language, you will lose sight of what makes the reply funny.

Here are the translations of the remark (12) and of the reply (13):

$$
\begin{aligned}
& \exists x(O x \wedge \forall y(O y \Rightarrow y=x) \wedge B\{\exists z(O z \wedge \forall y(O y \Rightarrow y=z) \wedge z>z\}) \\
& \sim \exists z(O z \wedge \forall y(O y \Rightarrow y=z) \wedge z>z)
\end{aligned}
$$

The joke is not funny, because we do not understand how (13) could be an answer to (12). It is as if the touchy owner had substituted (14) for (12):

$$
B\{\exists z(O z \wedge \forall y(O y \Rightarrow y=z) \wedge z>z)\} .
$$

But, as (12) is very different from (14), we do not see the point of the answer. It is not a joke - it is just a misunderstanding.

What is truly impressive is that Russell manages to give a logical explanation of the joke without destroying what makes it funny. In his notation, (12) would appear as:

$$
[(1 x)(O x)] B\{[(1 z)(O z)](1 z)(O z)>(1 x)(O x)\}
$$

And (14) as:

$$
B\{[(1 x)(O x)](1 x)(O x)>(1 x)(O x)\}
$$

We can now understand the cleverness of the owner. He took the guest's remark literally; he voluntarily neglected all the implicit shared conventions, and this refusal to understand the guest à demi-mot is precisely the point of the joke: it is a way for the owner to put his guest in his place. Now, the implicit shared conventions are manifested in (15) and (16) by the scope of the definite description. If you delete the scope symbol to retain only the perceptible part of the expression, you will get in (15) and (16) exactly the same sentence-sign. ${ }^{19}$ Thanks to logic, we can now understand how the yacht owner could have attributed to his guest the absurd belief that something can be greater than itself:

What the guest meant was, "the size that I thought your yacht was is greater than the size your yacht is"; the meaning attributed to him is, "I thought the size of your yacht was greater than the size of your yacht". (OD, Papers 4: 424)

Russell's analysis manages to explain how we can easily confuse (15) and (16), and why we cannot regard the exchange between the touchy owner and his guest as a mere

\footnotetext{
${ }^{19}$ The identities of the bound variables are determined by the scope operator. When these operators disappear, the two variables cannot be distinguished anymore. The ambiguity of the variable corresponds to the ambiguity of the pronoun "it" in "No, my yacht is not larger than it is."
} 
misunderstanding. The scope operators and the difference between primary and secondary occurrences are the logical means which allow us to understand what is funny in the joke. The difference with Frege, and with his contrast between serious and nonserious uses of languages, cannot be more apparent than it is here.

So, even though (to my knowledge) Russell does not point out the difference between the logical practice of $O D$ and the Fregean one, this difference has some major consequences in the way Russell deals with the puzzles. Frege's approach cannot account for the emergence of such a problem - they are, at best, understandable psychological difficulties which a logician must ignore and which disappear in a logically structured language. For Russell, even if they would not appear in the standard notation, Meinongian problems and Russellian jokes are really logical and must be a matter for logicians. Puzzles and jokes, like incomplete symbols, are both inextricably linguistic and logical notions. Wittgenstein was to be very sensitive to this kinship between philosophical problems and jokes, and very sensitive as well to the way Russell deals with puzzles. ${ }^{20}$

It's time to conclude. I hope to have made it clear why I think we cannot consider Russell just a "metaphysician of meaning". ${ }^{21}$ In $O D$, logic is applied to the relation between notational systems - at the same time, the working of the common languages (the English one, the ordinary mathematical one) is conceived as logically structured. The concept of the incomplete symbol is not a mere linguistic residue - it is a logical notion. What indeed is more "logical" at the time than the concept of scope which Russell connects so intimately in $O D$ with the definite description sign?

But I do not pretend to have determined here, in an entirely satisfactory way, what a Russellian incomplete symbol is. I do not pretend either to have described in an entirely satisfactory way how Russell articulates logic and language in (and after) $O D$. In fact, what I wanted to do was just the contrary: to show how ultimately puzzling for us is the concept of the incomplete symbol, and how it moves Russellian logical practice away from the distinction we make today, after Carnap, between object-language and metalanguage, between internal and external questions. Whatever is our interpretation of why Russell gave up his old denoting theory and adopted the new analysis of $O D$, we have to account for the fact that Russell's use of description symbols is logically very refined.

To remember the strangeness of the concept of the incomplete symbol seems to me important when we look at the Tractatus. I believe that Wittgenstein saw that $O D$ compels us to modify drastically our conception of analysis, of language, of logic. Many of the most puzzling Tractarian theses become, I think, more understandable when put in this context. It seems to me that we can consider many of these remarks ${ }^{22}$ as a mere commentary on what Russell does

\footnotetext{
${ }^{20}$ Philosophical Investigations (Oxford: Blackwell, 1958), §111, p. 47: “The problems arising through a misinterpretation of our forms of languages have the character of depth. They are deep disquietudes; their roots are as deep in us as the forms of our language and their significance is as great as the importance of our language. - Let us ask ourselves: why do we feel a grammatical joke to be deep? (And that is what the depth of philosophy is)."

${ }_{21}$ See G. Makin's great book, The Metaphysicians of Meaning: Russell and Frege on Sense and Denotation (London: Routledge, 2000).

${ }^{22}$ Look at the following Tractarian propositions: 3. 32: "The sign is a part of the symbol perceptible by the senses." 3. 321:

"Two different symbols can therefore have the sign (the written sign or the sound sign) in common — they then signify in different ways..." 3. 324: "Thus there easily arise the most fundamental confusions (of which the whole philosophy is full)..." 3. 326: "In order to recognize the symbol in the sign we must consider the significant use..." 3. 342: "In our notations there is indeed something arbitrary, but this is not arbitrary, namely that if we have determined anything arbitrarily, then something else must be the case...." 4. 002: "The silent adjustments to understand colloquial language are enormously complicated..." 5. 5563: "All propositions of our colloquial language are actually, just as they are, logically completely in order."
} 
in $O D$ and the Principia. ${ }^{23}$ But I will stop here. The development of this interpretation remains a story for another occasion.

\footnotetext{
${ }^{23}$ I developed an interpretation of the Tractatus along these lines in my Logique etLangage: Études sur le premier
} Wittgenstein (Paris: Vrin, 2002). 
